This item was submitted to Loughborough's Research Repository by the author.

Items in Figshare are protected by copyright, with all rights reserved, unless otherwise indicated.

\title{
Real-time energy management of the electric turbocharger based on explicit model predictive control
}

PLEASE CITE THE PUBLISHED VERSION

https://doi.org/10.1109/TIE.2019.2910033

PUBLISHER

(C) IEEE (Institute of Electrical and Electronics Engineers)

VERSION

AM (Accepted Manuscript)

LICENCE

All Rights Reserved

REPOSITORY RECORD

Zhao, Dezong, Richard Stobart, and Byron Mason. 2019. "Real-time Energy Management of the Electric Turbocharger Based on Explicit Model Predictive Control”. figshare. https://hdl.handle.net/2134/37337. 


\title{
Real-Time Energy Management of the Electric Turbocharger based on Explicit Model Predictive Control
}

\author{
Dezong Zhao, Senior Member, IEEE, Richard Stobart, Member, IEEE and Byron Mason
}

\begin{abstract}
The electric turbocharger is a promising solution for engine downsizing. It provides great potential for vehicle fuel efficiency improvement. The electric turbocharger makes engines run as hybrid systems so critical challenges are raised in energy management and control. This paper proposes a real-time energy management strategy based on updating and tracking of the optimal exhaust pressure setpoint. Starting from the engine characterisation, the impacts of the electric turbocharger on engine response and exhaust emissions are analysed. A multivariable explicit model predictive controller is designed to regulate the key variables in the engine air system, while the optimal setpoints of those variables are generated by a high level controller. The two-level controller works in a highly efficient way to fulfill the optimal energy management. This strategy has been validated in physical simulations and experimental testing. Excellent tracking performance and sustainable energy management demonstrate the effectiveness of the proposed method.
\end{abstract}

Index Terms-Electric turbocharger, real-time energy management, explicit model predictive control

\section{INTRODUCTION}

$\mathbf{T}$ HE growing concern of global warming due to the greenhouse gas emissions have raised great attention in improving the energy efficiency of the transport sector. In 2015, the transport sector consumed 27\% global energy [1] and contributed $23 \%$ global $\mathrm{CO}_{2}$ emissions [2]. Internal combustion engines (ICE) will continue to dominate transport systems for several decades. Nowadays more than $95 \%$ of transport energy are consumed by ICE and this figure is predicted to be around $90 \%$ by 2040 [3]. In ICE, 30-37\% fuel energy is lost in exhaust gas, this figure can be significantly reduced by engine downsizing and energy recovery. This target can be achieved using advanced turbocharger technologies [4].

In traditional turbochargers, the turbine is driven by the exhaust gas, and the compressor connected to the turbine is rotated. As a result, the fresh air is compressed raising intake manifold pressure. This layout recovers part of the exhaust

Manuscript received July 13, 2018; revised December 25, 2018, February 1, 2019 and February 28, 2019; accepted March 8, 2019. This work was supported in part by the Low Carbon Vehicle IDP4 Programme of Innovate UK under Grant TP14/LCV/6///BG011L and in part by the EPSRC-UKRI Innovation Fellowship scheme of Engineering and Physical Sciences Research Council of U.K. under Grant EP/S001956/1. (Corresponding author: Dezong Zhao).

The authors are with the Department of Aeronautical and Automotive Engineering, Loughborough University, Loughborough LE11 3TU, U.K. (e-mail: d.zhao@lboro.ac.uk, r.k.stobart@lboro.ac.uk, b.mason2@lboro.ac.uk).

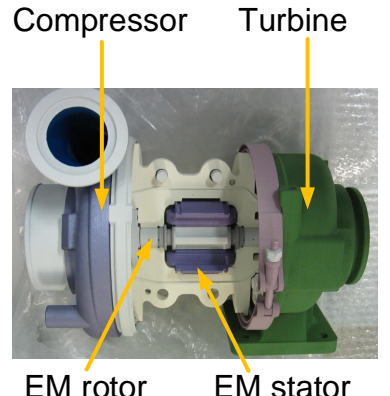

(a)

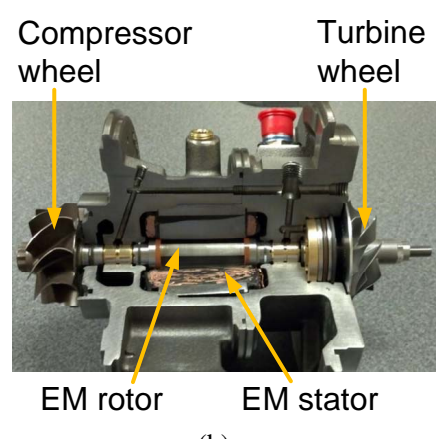

(b)
Fig. 1. 3D prototype model and real device of the Electric Turbocharger Assist. (a) 3D prototype model. (b) Real device.

gas energy that would otherwise will be lost, but has two main drawbacks. First, the amount of recovered energy at a specific engine operating point is limited by the compressor power demand to deliver the desired torque. Second, the engine torque response is constricted at low engine speeds due to the turbo lag. The electric turbocharger (ET) is a promising solution to overcome these drawbacks. In the ET, an extra-high-speed electric machine (EM) is mounted on the shaft connecting the turbine and compressor wheels. This layout improves the fuel efficiency by running the EM as a generator, and improves the transient response by running the EM as a motor. Recently, a consortium led by Caterpillar developed an ET for heavy-duty diesel engines, named the Electric Turbocharger Assist (ETA). The 3D prototype model and the real device of the ETA are illustrated in Fig. 1. The ET provides multiple benefits which are elaborated in the following.

(1) Improved transient response. In periods of low boost, the compressor is driven electrically and therefore the transient response is improved. Caterpillar [5] and Mitsubishi Heavy Industries (MHI) [6] have demonstrated that the ET improves the torque response by $50 \%$ or more compared to traditional turbochargers. The ET has also been used in Formula 1 race cars to boost acceleration [7].

(2) Engine downsizing. The ET enables engine downsizing through improved air delivery, whereby a smaller capacity engine can provide the power previously delivered by a larger engine. In [5], Caterpillar downsized a $9.3 \mathrm{~L}$ heavy-duty diesel engine to $7.01 \mathrm{~L}$ using the ETA. In downsized engines, the average engine operating point is closer to its high fuel efficiency zone. Extra fuel benefits can be obtained through reduced 
engine mass, reduced heat transfer, and reduced friction.

(3) Improved fuel efficiency. Through the ET, the surplus exhaust gas energy is recovered. Pankl Turbosystems [8] reported a reduction of $\mathrm{CO}_{2}$ emissions by $5.3 \mathrm{~g} / \mathrm{km}$ under real driving conditions. In [9], the ET is evaluated on a $4.75 \mathrm{~L}$ diesel engine, while a $6.7 \%$ fuel economy benefit is observed in the engine high power operating region, and the value is $1.2 \%$ when the engine runs under C-WTVC driving cycles.

(4) Low cost energy recovery solution. The recovered exhaust gas energy can be used to assist the powertrain traction. The system in this layout is called the electric turbocompounding (ETC). Compared to other waste heat recovery technologies such as the thermoelectric generator (TEG) and Organic Rankine Cycle (ORC), the ETC is a more economical solution. The disadvantage of the TEG is the expensive materials and low energy conversion efficiency $(<4 \%)[10]$. The main obstacle in developing the ORC is the high cost in retrofitting due to its complexity. The cost of installing a 20-50 $\mathrm{kW}$ ORC system is $1500-2000 \$ / \mathrm{kW}$ [11]. The ETC is more cost effective because of easy assembling [12].

(5) Applicable to hybrid electric vehicles (HEV). The ET has gained its popularity in HEV because it provides an additional freedom in vehicle energy recovery [13]. The complete description of applying the ET on HEV is given in [14]. By applying an ET called e-boost on a Mercedes-Benz E-Class hybrid car, a $0.7 \%$ fuel economy benefit has been observed in the FDC driving cycle [15]. Moreover, the e-boost offers up to $4 \%$ reduction in acceleration time.

The application of ETs have been generalised from road vehicles to marine vehicles [12]. Several types of EMs including the switched reluctance machine (SRM) [16], induction machine (IM) [17], and permanent magnet synchronous machine (PMSM) [18] have been used for the manufacturing of the EM within the ET. Several milestone studies on the characterisation have also been completed as following. The engine fuel efficiency is impacted by the pumping losses which vary when the ET works as a motor or generator [19]. It has been shown that the ET optimal working condition can be determined by the exhaust pressure [20]. The ET decouples the intake manifold and exhaust manifold, which has been verified by multiple studies [21]. Furthermore, the controllability of the ET has been proved in [22].

Efficient real-time energy management and control are the keys to the success of the ET. They are required to find and track the optimal exhaust pressure. Meanwhile, maintaining the state-of-charge (SOC) level of the onboard battery in a reasonable range is essential. Real-time energy management and control of the ET are less developed compared to the progress in its manufacturing and characterisation. In [23], the ET is controlled in an open loop manner. In [24], only the air-fuel ratio (AFR) is controlled rather than the exhaust pressure. In [25], the ET and the other actuators are controlled independently without considering the interactions. None of them settled the energy management problem. This paper presents an attempt to address the gap.

Three critical physical constraints have to be considered in controller design. On the inputs side, the variable geometry turbine (VGT), exhaust gas recirculation (EGR) and the EM

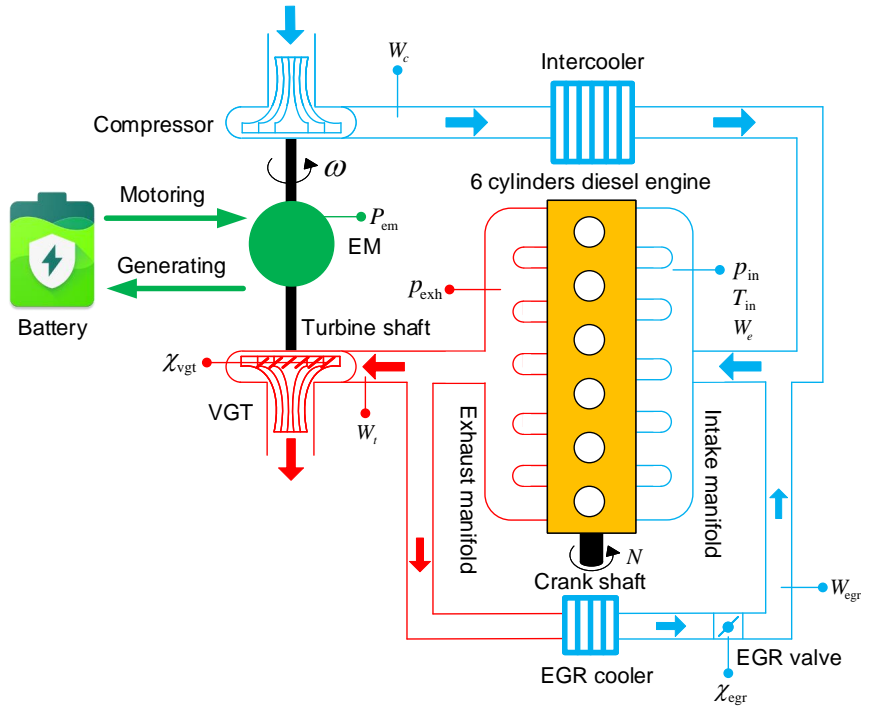

Fig. 2. Electric turbocharged diesel engine.

TABLE I

NOMENCLATURE

\begin{tabular}{lll}
\hline Variable & Description & $\mathrm{Unit}$ \\
\hline$N$ & Engine speed & $\mathrm{r} / \mathrm{min}$ \\
$\omega$ & Turbine speed & $\mathrm{rad} / \mathrm{s}$ \\
$T_{L}$ & Engine load & $\mathrm{N} \cdot \mathrm{m}$ \\
$W_{f}$ & Engine fuelling rate & $\mathrm{kg} / \mathrm{s}$ \\
$W_{e}$ & Total mass flow rate to cylinders & $\mathrm{kg} / \mathrm{s}$ \\
$W_{c}$ & Fresh air flow rate & $\mathrm{kg} / \mathrm{s}$ \\
$W_{\text {egr }}$ & EGR mass flow rate & $\mathrm{kg} / \mathrm{s}$ \\
$W_{t}$ & Gas gas mass flow rate through the turbine & $\mathrm{kg} / \mathrm{s}$ \\
$P_{c}$ & Compressor power & $\mathrm{kW}$ \\
$P_{t}$ & Turbine power & $\mathrm{kW}$ \\
$P_{b}$ & Engine brake power & $\mathrm{kW}$ \\
$P_{\text {em }}$ & EM power & $\mathrm{kW}$ \\
$T_{\text {in }}$ & Intake manifold temperature & $\mathrm{K}$ \\
$T_{\text {exh }}$ & Exhaust manifold temperature & $\mathrm{K}$ \\
$p_{\text {in }}$ & Boost pressure & $\mathrm{kPa}$ \\
$p_{\text {exh }}$ & Exhaust manifold pressure & $\mathrm{kPa}$ \\
$p_{a}$ & Ambient pressure & $\mathrm{kPa}$ \\
$V_{d}$ & Engine displacement & $\mathrm{m}$ \\
$J$ & Turbine shaft moment of inertia & $\mathrm{kg} \cdot \mathrm{m}^{2}$ \\
$\eta_{c}$ & Compressor isentropic efficiency & - \\
$\eta_{t}$ & Turbine isentropic efficiency & - \\
$\eta_{v}$ & Volumetric efficiency & - \\
$\eta_{m}$ & Turbocharger mechanical efficiency & - \\
$\chi_{\text {egr }}$ & EGR valve opening & - \\
$\chi_{\text {vgt }}$ & VGT vane opening & - \\
$R_{g}$ & Specific gas constant, 0.292 & - \\
\hline & & \\
\hline & & - \\
& & \\
\hline
\end{tabular}

are the primary actuators. VGT and EGR can both actuate from fully closed to fully open position, which are normalised from 0 to 1. Moreover, the EM can only work in the range between the maximum motoring power and maximum generating power. All the constraints on inputs are considered in designing the multi-variable controller. On the outputs side, the exhaust pressure is a critical variable. With increasing exhaust pressure, additional pumping work is required, and less energy will be available to boost intake manifold pressure. This can lead to an increase in fuel consumption, particulate matter (PM) and CO emissions [20]. A too high exhaust pressure may stall the engine. In this work, the allowable maximum exhaust pressure is calculated in the calibration. The third constraint 


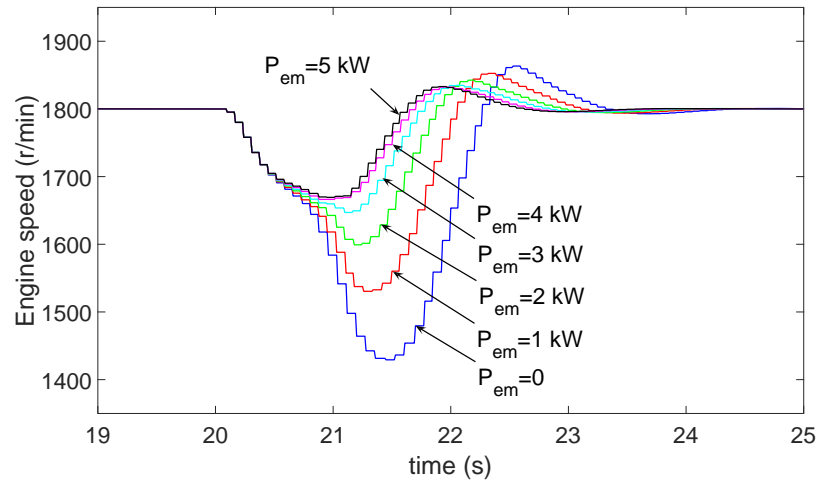

(a)

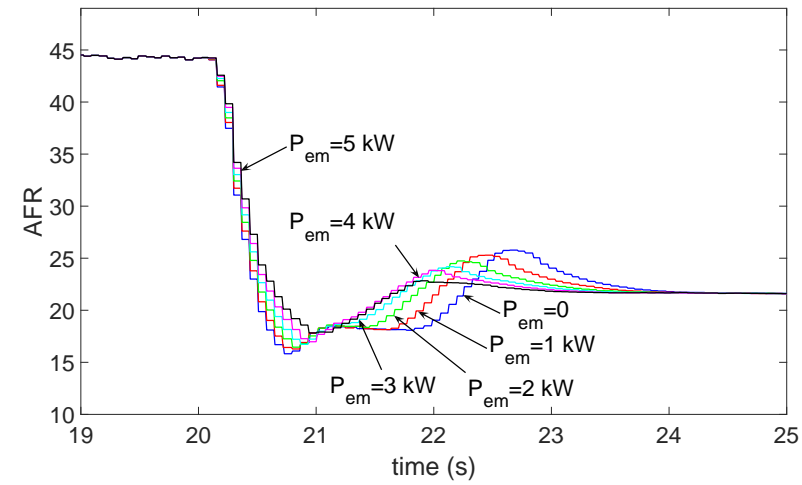

(b)

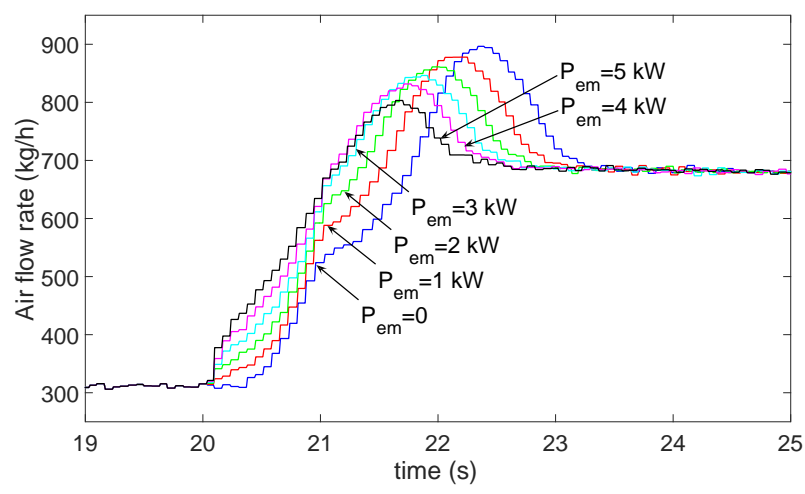

(c)

Fig. 3. Performance evaluation in transients from $(1800 \mathrm{r} / \mathrm{min}, 120 \mathrm{~N} \cdot \mathrm{m})$ to $(1800 \mathrm{r} / \mathrm{min}, 800 \mathrm{~N} \cdot \mathrm{m})$. (a) N. (b) AFR. (c) $W_{c}$.

is thermal management due to the EM running at extra-high speeds in a compact housing. This problem is mitigated by employing a high efficient oil-cooling system [22].

This work is based on an 7.01 L ETA-equipped heavy-duty diesel engine. An integrated real-time energy management strategy is designed for both transients and steady state. The impact of ETA on engine acceleration and exhaust emissions are analysed. The energy management strategy is presented in a hierarchical structure. At high level, the desired exhaust pressure is computed to distribute energy flows in the optimal way. At the lower level, the actuators are regulated using the explicit model predictive control (EMPC) method to achieve the desired energy flow distribution in a centralized way.

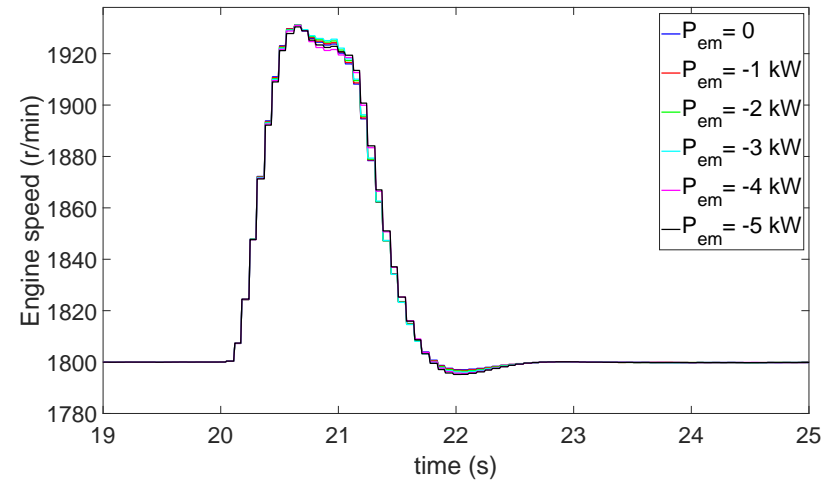

(a)

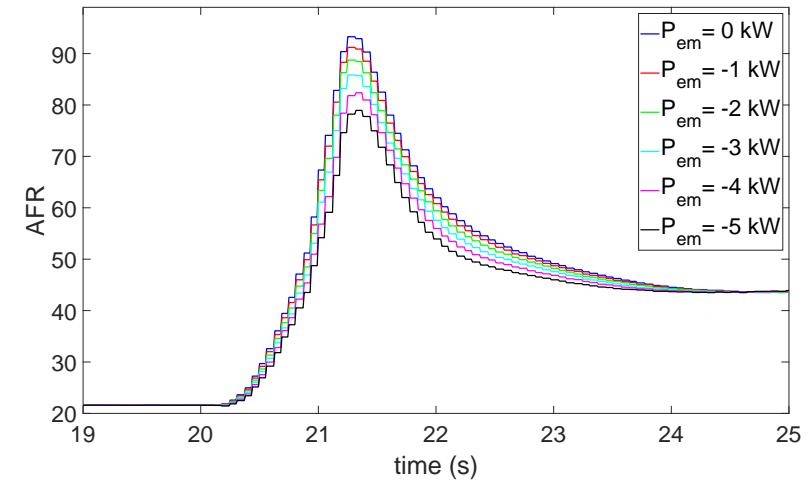

(b)

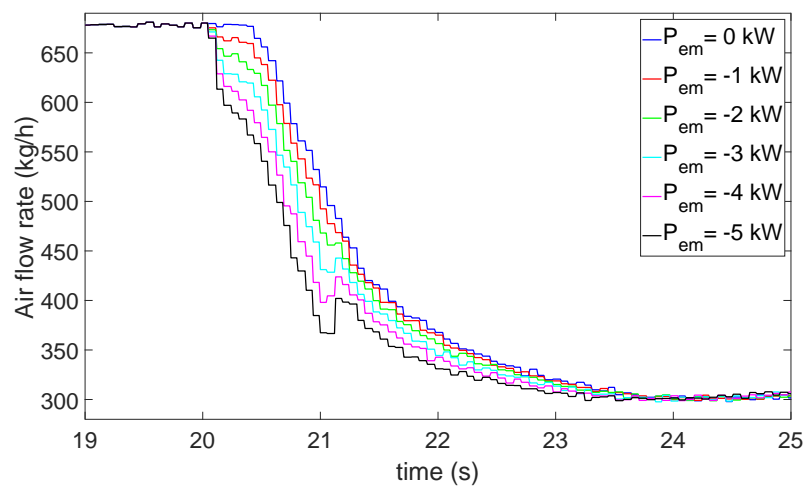

(c)

Fig. 4. Performance evaluation in transients from $(1800 \mathrm{r} / \mathrm{min}, 800 \mathrm{~N} \cdot \mathrm{m})$ to $(1800 \mathrm{r} / \mathrm{min}, 120 \mathrm{~N} \cdot \mathrm{m})$. (a) N. (b) AFR. (c) $W_{c}$.

\section{SYSTEM DESCRIPTION AND ANALYSIS}

\section{A. System Description}

The diagram of an electric turbocharged diesel engine (ETDE) is illustrated in Fig. 2, while the critical variables and parameters are listed in Table I. The ETA is a single stage turbocharger consisting of a VGT, an EM and a compressor, which are mounted on the same turbine shaft. The expansion of the exhaust gas across the VGT rotates the compressor, and thereafter the fresh air is pumped into the intake manifold. When the EM runs in generating, some of the exhaust gas energy is used to charge the battery so the turbine speed drops. This raises $p_{\text {exh }}$ and $T_{\text {exh }}$. On the other hand, when the EM runs in motoring, $p_{\text {exh }}$ and $T_{\text {exh }}$ both drops. The VGT moves toward closed to ensure sufficient energy is used for air compression. 
A SRM is used as the EM because of its simple structure and the resulting low cost. The SRM has a rated power of $5 \mathrm{~kW}$.

According to the conservation laws of mass and energy, the air system dynamics can be determined by the pressure and mass changes in the intake and exhaust manifolds: $\dot{p}_{\text {in }}, \dot{p}_{\text {exh }}$, $\dot{m}_{\text {in }}$ and $\dot{m}_{\text {exh }}$ [25]. Strong nonlinearities exist for the mass flow exchanges among the EGR, VGT, compressor and manifolds. The mass flow rates can be expressed as:

$$
\begin{aligned}
W_{\text {in }} & =W_{e}+W_{f} \\
W_{\text {exh }} & =W_{\text {egr }}+W_{t} \\
W_{e} & =f\left(p_{\text {in }}, T_{\text {in }}, \eta_{v}, N\right) \\
W_{\text {egr }} & =f\left(p_{\text {in }}, p_{\text {exh }}, \chi_{\text {egr }}\right) \\
W_{t} & =f\left(p_{\text {exh }}, T_{\text {exh }}, \chi_{\text {vgt }}\right) \\
W_{c} & =f\left(p_{\text {in }}, \omega\right)
\end{aligned}
$$

where $W_{e}$ is modeled by the speed-density equation; $W_{\text {egr }}$ is modeled using the standard orifice equation; $W_{t}$ and $W_{c}$ are modeled as nonlinear functions with respect to the efficiencies $\eta_{t}$ and $\eta_{c}$. The dynamics of the turbocharger is represented by the mechanical equation:

$$
\dot{\omega}=\left(\eta_{m}\left(P_{t}+P_{\mathrm{em}}\right)-P_{c}\right) /(J \omega)
$$

where $\eta_{m}$ quantifies the bearing power losses and windage losses. The power of both compressor and turbine are represented by maps with respect to $\eta_{t}$ and $\eta_{c}$ :

$$
\begin{aligned}
& P_{t}=f\left(W_{t}, T_{\text {exh }}, p_{\text {exh }}, \eta_{t}\right) \\
& P_{c}=f\left(W_{c}, p_{\text {in }}, p_{a}, \eta_{c}\right) .
\end{aligned}
$$

\section{B. Analysis on Controllability and Observability}

The ETA provides an additional degree of freedom in regulating air system, but also makes the control more complicated. $p_{\text {in }}$ and $W_{c}$ are controlled in conventional diesel engines, which are linearly independent [26]. However, with the introduction of the EM, improving transient response is an additional target and therefore, one more independent output has to be identified. By segregating the entire engine operating region into multiple local zones, the ETDE model in one local zone can be represented as a linear model:

$$
\left\{\begin{array}{l}
x(k+1)=A x(k)+B u(k) \\
y(k)=C x(k)
\end{array}\right.
$$

where $x \in \mathbb{R}^{n}, u \in \mathbb{R}^{3}$, and $y \in \mathbb{R}^{3}$ are the state vector, input vector, and output vector, respectively; $A, B$, and $C$ are coefficient matrices to be identified. It is required that (2) is controllable and observable. In other words, all the states should be linearly independent and can be measured/estimated. Here $n=3$ is selected and therefore, $x$ and $y$ are linearly correlated. Consequently, the problem is transferred to find an extra observable output which is independent of $p_{\text {in }}$ and $W_{c}$.

1) Controllability: The enthalpy of exhaust gas speeds up the turbine, which is a relatively slow process. The resulting rotated compressor transfers this kinetic energy to the fresh air, which is a fast process. This means that the ETA decouples the exhaust and intake manifolds and therefore, $p_{\text {exh }}$ can be selected as the extra output [21]. $p_{\text {exh }}$ is the critical variable impacting the pumping loss, so it is the key parameter to be optimised in improving the fuel efficiency [27].
2) Observability: The three outputs, $p_{\text {in }}, p_{\text {exh }}$ and $W_{c}$ can all be measured by sensors [28]. To reduce the cost of transducers, it is more popular to estimate $W_{c}$ using observers [29]. In steady state or slow transients, $W_{c}+W_{\text {egr }}=W_{e}$ is held and $W_{e}$ can be computed by $W_{e}=\eta_{v} p_{\text {in }} V_{d} N /\left(120 T_{\text {in }} R_{g}\right)$, so $W_{c}$ can be replaced by $W_{\text {egr }}$ [30]. The estimation of the simultaneous $W_{\text {egr }}$ value has been well developed.

As a summary, the inputs and outputs are selected as

$$
\begin{aligned}
& u=\left[\begin{array}{lll}
\chi_{\text {vgt }}, & P_{\text {em }}, & \chi_{\text {egr }}
\end{array}\right]^{\mathrm{T}} \\
& y=\left[\begin{array}{lll}
p_{\text {in }}, & p_{\text {exh }}, & W_{\text {egr }}
\end{array}\right]^{\mathrm{T}}
\end{aligned}
$$

and thereafter (2) is guaranteed to be a controllable and observable system.

\section{Analysis on Transient Performance}

The impacts of ETA on engine response and exhaust emissions are evaluated in both load acceptance and load shedding through experimental testing, while the engine runs at a speed of $1800 \mathrm{r} / \mathrm{min}$. The opening of VGT and EGR are set as constants: $\chi_{\mathrm{vgt}}=0.5$ and $\chi_{\mathrm{egr}}=0.3$.

In load acceptance, $T_{L}$ rises linearly from $120 \mathrm{~N} \cdot \mathrm{m}$ at 20 $\mathrm{s}$ to $800 \mathrm{~N} \cdot \mathrm{m}$ at $21 \mathrm{~s}$. The desired AFR, denoted as AFR ${ }^{\star}$, decreases almost linearly in transients. Applying different $P_{\mathrm{em}}$ from $0 \mathrm{~kW}$ (EM off) to $5 \mathrm{~kW}$ (the maximum motoring power) in transients, testing results are illustrated in Fig. 3. The engine responses are given in Fig. 3(a), where $N$ drops from 1800 $\mathrm{r} / \mathrm{min}$ to $1429 \mathrm{r} / \mathrm{min}$ and requires $4.5 \mathrm{~s}$ to recover when the EM is off. With the increasing $P_{\mathrm{em}}$, the speed drop is significantly reduced and $N$ recovers more quickly. In the case of $P_{\mathrm{em}}=$ $5 \mathrm{~kW}, N$ drops to the minimum value of $1669 \mathrm{r} / \mathrm{min}$ and takes $3.2 \mathrm{~s}$ to recover. The speed drop magnitude and speed recovery time have been improved by $64.7 \%$ and $28.9 \%$, respectively. The acceleration is caused by improved AFR as shown in Fig. $3(\mathrm{~b})$. The $\mathrm{AFR}^{\star}$ at low load $(1800 \mathrm{r} / \mathrm{min}, 120 \mathrm{~N} \cdot \mathrm{m})$ and high load (1800 r/min, $800 \mathrm{~N} \cdot \mathrm{m})$ are 44.3 and 21.5 , respectively. Before $20.4 \mathrm{~s}$, the AFR has drift but not far from the $\mathrm{AFR}^{\star}$ at every $P_{\mathrm{em}}$ setting, indicating the compressed air is enough. It can also be observed in Fig. 3(a) that the speed trajectories are quite close before $20.4 \mathrm{~s}$. After $20.4 \mathrm{~s}$, the AFR drops far below the $\mathrm{AFR}^{\star}$ so more air boosting assistance is necessary. In the transient period of [20 s, $21 \mathrm{~s}$ ], AFR holds the highest value in the case of $P_{\mathrm{em}}=5 \mathrm{~kW}$ and therefore the best air flow delivery is achieved, showing the effectiveness of the ETA. This is also illustrated in Fig. 3(c). When the EM runs at the maximum motoring power, the response of $W_{c}$ is about $0.6 \mathrm{~s}$ faster than when the EM is off. Moreover, the EM assistance introduces less overshoot on $W_{c}$, where the peak value reduces from $897 \mathrm{~kg} / \mathrm{h}$ to $803 \mathrm{~kg} / \mathrm{h}$. Less unnecessary but faster fresh air delivery produces another benefit, which is the reduced nitrogen oxides $\left(\mathrm{NO}_{x}\right)$ emission. With the increasing $P_{\mathrm{em}}$, the mixture of air and fuel is less lean and therefore the peak combustion temperature drops. This directly contributes to the $\mathrm{NO}_{x}$ emission reduction.

In the load shedding case, $T_{L}$ drops linearly from 800 $\mathrm{N} \cdot \mathrm{m}$ at $20 \mathrm{~s}$ to $120 \mathrm{~N} \cdot \mathrm{m}$ at $21 \mathrm{~s}$, and the $\mathrm{AFR}^{\star}$ increases almost linearly. Applying different $P_{\mathrm{em}}$ from $0 \mathrm{~kW}$ to $-5 \mathrm{~kW}$ (the maximum generating power) in the transient period, the 


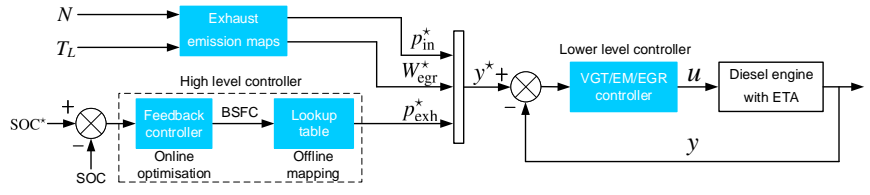

Fig. 5. Engine control and energy management structure.

testing results are illustrated in Fig. 4. As shown in Fig. 4(a), the peak value of $N$ is around $1930 \mathrm{r} / \mathrm{min}$ and the recovery time is aound $2.7 \mathrm{~s}$ for all $P_{\mathrm{em}}$ settings. The variation on the overshooting or recovery time of $N$ is less than $4 \%$, which is fairly small. It is because the AFR is higher than $\mathrm{AFR}^{\star}$ in transients for all $P_{\mathrm{em}}$ settings, as shown in Fig. 4(b). The sufficient mixture of air and fuel guarantees efficient combustion so the engine response is not significantly affected. When the EM runs at the maximum generating power in load shedding, $W_{c}$ is reduced more sharply. It is illustrated in Fig. 4(c) that the ETA provides up to $0.6 \mathrm{~s}$ faster response on $W_{c}$. Running the EM in generating mode prevents unnecessary air delivery and leads to the reduction of $\mathrm{NO}_{x}$ emission. This indicates that recovering exhaust gas energy in load shedding has no compromise on engine response or emissions. The analysis in transients suggest that the ETA should run at the maximum motoring power in load acceptance and run at the permissible maximum generating power in load shedding.

\section{Real-Time Energy Management STRATEGY DESIGN}

Real-time energy management is to distribute the energy flows in an optimal way. It is achieved by online generating and tracking of the optimal setpoints of $p_{\text {in }}, p_{\text {exh }}$ and $W_{\text {egr }}$, denoted as $p_{\text {in }}^{\star}, p_{\text {exh }}^{\star}$ and $W_{\text {egr }}^{\star}$. According to the vehicle exhaust emission standards relating to $\mathrm{NO}_{x}$ and $\mathrm{PM}, p_{\text {in }}^{\star}$ and $W_{\text {egr }}^{\star}$ are generated from offline characterisation. To maintain the battery SOC within a special range while minimising the brake specific fuel consumption (BSFC), $p_{\text {exh }}^{\star}$ would be updated online. The proposed strategy consists of high and lower level controllers as shown in Fig. 5, where $\mathrm{SOC}^{\star}$ is the desired value of SOC. The high level controller generates the optimal setpoints which would be tracked by employing the lower level controller.

\section{A. Lower Level Controller Design}

The EMPC is selected as the lower level controller for its capability in dealing with internal couplings and external constraints. The controller is synthesized offline using the multiparametric quadratic programming (mpQP) method based on a linear model. The model is identified from calibration data. Afterwards, the synthesized controller will be run on the engine control unit (ECU). In the online implementation, the optimal control laws will be invoked according to engine feedback signals. The complete procedure in compiling and implementing the EMPC is illustrated in Fig. 6.

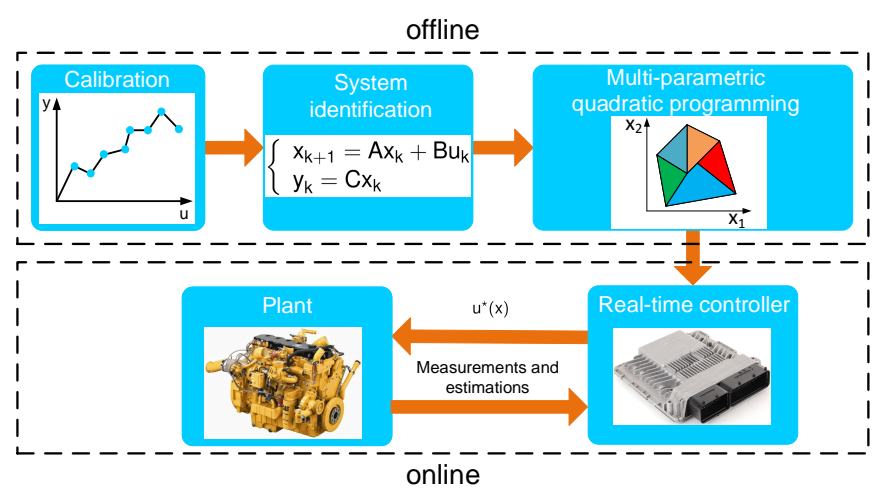

Fig. 6. Explicit model predictive control solution.

1) Problem Formulation: Based on the system model (2), the control problem is defined as the following optimisation problem:

$$
\begin{aligned}
U^{\star}(k)=\operatorname{argmin} & \sum_{i=0}^{H_{p}}\left\|y(k+i)-y^{\star}(k)\right\|_{Q}^{2}+\|\Delta u(k+i)\|_{R}^{2} \\
\text { s.t. } & x(k+1)=A x(k)+B u(k) \\
& u(k)=u(k-1)+\Delta u(k) \\
& y(k)=C x(k) \\
& u_{\min } \leq u \leq u_{\max } \\
& y_{\min } \leq y \leq y_{\max }
\end{aligned}
$$

where

$$
\begin{aligned}
U(k) & \triangleq\left[\Delta u^{\mathrm{T}}(k), \ldots, \Delta u^{\mathrm{T}}\left(k+H_{c}-1\right)\right]^{\mathrm{T}} \\
\Delta u(k+i) & =\Delta u\left(k+H_{c}-1\right), \quad i=H_{c}, \ldots, H_{p} \\
Q & =Q^{\mathrm{T}}>0 \\
R & =R^{\mathrm{T}}>0 \\
\|x\|_{Q}^{2} & =x^{\mathrm{T}} Q x .
\end{aligned}
$$

The constraints on $u$ are the amplitude boundaries of the control signals, and the constraints on $y$ represent the physical ranges of the outputs, where $u$ and $y$ have been defined in (3). $H_{p}$ and $H_{c}$ are the prediction horizon and control horizon respectively, where $H_{p} \geq H_{c}$ is held.

2) Model Identification: The system model (2) can be represented by

$$
\left\{\begin{array}{l}
x(k+1)=A(\theta) x(k)+B(\theta) u(k) \\
y(k)=C(\theta) x(k)
\end{array}\right.
$$

where $A, B$ and $C$ are functions of a parameter vector $\theta$. Model identification is to decide these matrices by estimating $\theta$ from input-output data. Therefore, the identification problem is formulated as minimising

$$
V_{m}(\theta)=\frac{1}{m} \sum_{k=1}^{m}|\epsilon(k, \theta)|^{2}
$$

where

$$
\begin{aligned}
\epsilon(k, \theta) & =y(k)-\hat{y}(k \mid \theta) \\
\hat{x}(k+1 \mid \theta) & =A(\theta) \hat{x}(k \mid \theta)+B(\theta) u(k) \\
\hat{y}(k \mid \theta) & =C(\theta) \hat{x}(k \mid \theta)
\end{aligned}
$$



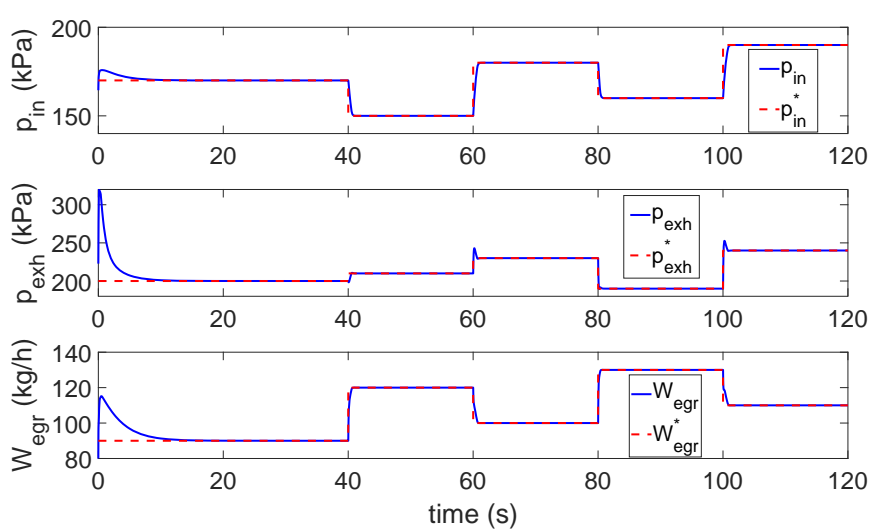

Fig. 7. Evaluation of the EMPC at $1800 \mathrm{r} / \mathrm{min}, 120 \mathrm{~N} \cdot \mathrm{m}$ in simulation.

while $m$ is the number of training data samples. The prediction error minimisation method (PEM) is employed to estimate $\theta$ [31], while $\theta$ is initialised using the numerical algorithm for subspace state space system identification (N4SID) [32]. $\theta$ is iteratively optimised based on the least-square method, until the variation on $V_{m}(\theta)$ is sufficiently small [33]. In this work, the ssest solver in MATLAB System Identification Toolbox is used to identify the model. Two independent data sets are generated for model identification. As an example, in the experimental training and validation data at $(1800 \mathrm{r} / \mathrm{min}, 120$ $\mathrm{N} \cdot \mathrm{m}$ ), the sampling frequency was $100 \mathrm{~Hz}$ for both datasets. The time window length was $600 \mathrm{~s}$ for training data and 900 $\mathrm{s}$ for validation data. The constraints of inputs are

$$
\begin{aligned}
u_{\min } & =\left[\begin{array}{lll}
0.1 & -1.5 \mathrm{~kW} & 0
\end{array}\right]^{\mathrm{T}} \\
u_{\max } & =\left[\begin{array}{lll}
0.5 & 4.5 \mathrm{~kW} & 0.5
\end{array}\right]^{\mathrm{T}} .
\end{aligned}
$$

The identified matrices are

$$
\begin{aligned}
& A=\left[\begin{array}{ccc}
1.6597 & 0.2795 & 0.3861 \\
0.0213 & 0.9456 & 0.0025 \\
-2.9344 & -0.9853 & -0.4742
\end{array}\right] \\
& B=\left[\begin{array}{ccc}
0.0325 & -0.0438 & 0.2741 \\
-0.0110 & 0.0006 & 0.0026 \\
-0.0960 & 0.1526 & -1.1150
\end{array}\right] \\
& C=\left[\begin{array}{ccc}
17.2 & 576.2 & 20.1 \\
246.2 & 1314.1 & 55.3 \\
-926.0 & 458.3 & -165.6
\end{array}\right]
\end{aligned}
$$

and the system is both controllable and observable:

$$
\begin{aligned}
& \operatorname{rank}\left[B, A B, A^{2} B\right]=3 \\
& \operatorname{rank}\left[C ; C A ; C A^{2}\right]=3 .
\end{aligned}
$$

3) Controller Synthesis: Online optimisation in standard MPC is computationally intensive. This issue can be addressed by solving (4) offline over predefined ranges. The optimisation problem (4) can be re-formulated as [34], [35]

$$
\begin{aligned}
U^{\star}(k)=\operatorname{argmin} & \frac{1}{2} U(k)^{\mathrm{T}} H U(k)+x(k)^{\mathrm{T}} F U(k) \\
\text { s.t. } & G U(k) \leq W+E x(k)
\end{aligned}
$$

where $H, F, G, W, E$ are algebraically transformed from $Q, R$ and system model (2). Introducing $z(k) \triangleq U(k)+H^{-1} F^{\mathrm{T}} x(k)$, then (11) is transformed into the following optimisation problem:

$$
\begin{aligned}
z^{\star}(k)=\operatorname{argmin} & \frac{1}{2} z(k)^{\mathrm{T}} H z(k) \\
\text { s.t. } & G z(k) \leq W+S x(k)
\end{aligned}
$$

where $S \triangleq E+G H^{-1} F^{\mathrm{T}}$. The solution $z^{\star}(k)$ is a continuous piecewise affine (PWA) function defined over a polyhedral partition, so is the $U^{\star}(k)$ :

$$
U^{\star}(k)= \begin{cases}f_{1} x(k)+g_{1} & \text { if } h_{1} x(k) \leq k_{1} \\ & \vdots \\ f_{q} x(k)+g_{q} & \text { if } h_{q} x(k) \leq k_{q}\end{cases}
$$

where the inequalities mean the constraints on the polygons, and $q$ is the number of polygons.

The MATLAB Model Predictive Control Toolbox is used to generate EMPC control laws. The control laws are stored in look-up tables within the ECU. In online implementation, control laws are read from the table without conducting any optimisation. This grants the EMPC an advantage of reduced computation time meanwhile maintaining identical performance with the MPC. In real-time control, only the first component of $U^{\star}(k)$ would be applied:

$$
u(k)=\left[\begin{array}{llll}
I & 0 & \ldots & 0
\end{array}\right] U^{\star}(k) .
$$

In the next sampling step, $U^{\star}(k+1)$ is called from the look-up table again, and $u(k+1)$ is updated accordingly.

In this work, $H_{p}$ was set as 10 , while increasing $H_{p}$ has limited impact on control performance. $H_{c}$ was set as 1 to avoid aggressive control actions. The output weight matrix was set as $Q=\operatorname{diag}([50,50,50])$ by heuristics. The input weight matrix was set as $R=\operatorname{diag}([1,1,1])$. $R$ has a small value because the magnitude of inputs are not treated as prices [36].

In Fig. 7, the performance of EMPC at $1800 \mathrm{r} / \mathrm{min}, 120$ $\mathrm{N} \cdot \mathrm{m}$ in simulation is illustrated. The command signals vary between $y_{\min }^{\star}=\left[\begin{array}{lll}150 \mathrm{kPa} & 190 \mathrm{kPa} & 90 \mathrm{~kg} / \mathrm{h}\end{array}\right]^{\mathrm{T}}$ and $y_{\max }^{\star}=$

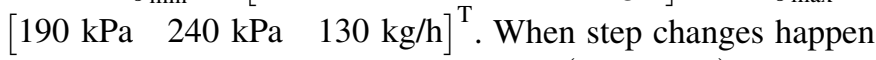
on $y^{\star}$, the tracking is fast in spite of $y_{i}^{\star}(i=1,2,3)$ change in different directions. The simulations validate the effectiveness of the EMPC and build confidence for experimental testing.

\section{B. High Level Controller Design}

The high level controller generates $p_{\mathrm{exh}}^{\star}$ according to offline mapping and online optimisation. In the offline mapping, the relationships among $p_{\mathrm{exh}}^{\star}, P_{\mathrm{em}}$ and BSFC are found. In the online optimisation, a feedback controller regulates the battery SOC while maximising the energy efficiency.

1) Problem Formulation: In the ETA, the following power balance equation holds:

$$
P_{c}=P_{\mathrm{em}}+P_{t} .
$$

To reveal the impact of battery SOC deviation on engine running, an equivalent power is defined as

$$
P_{\mathrm{eq}}=s(\mathrm{SOC}) P_{\mathrm{em}}+P_{t} \text {. }
$$




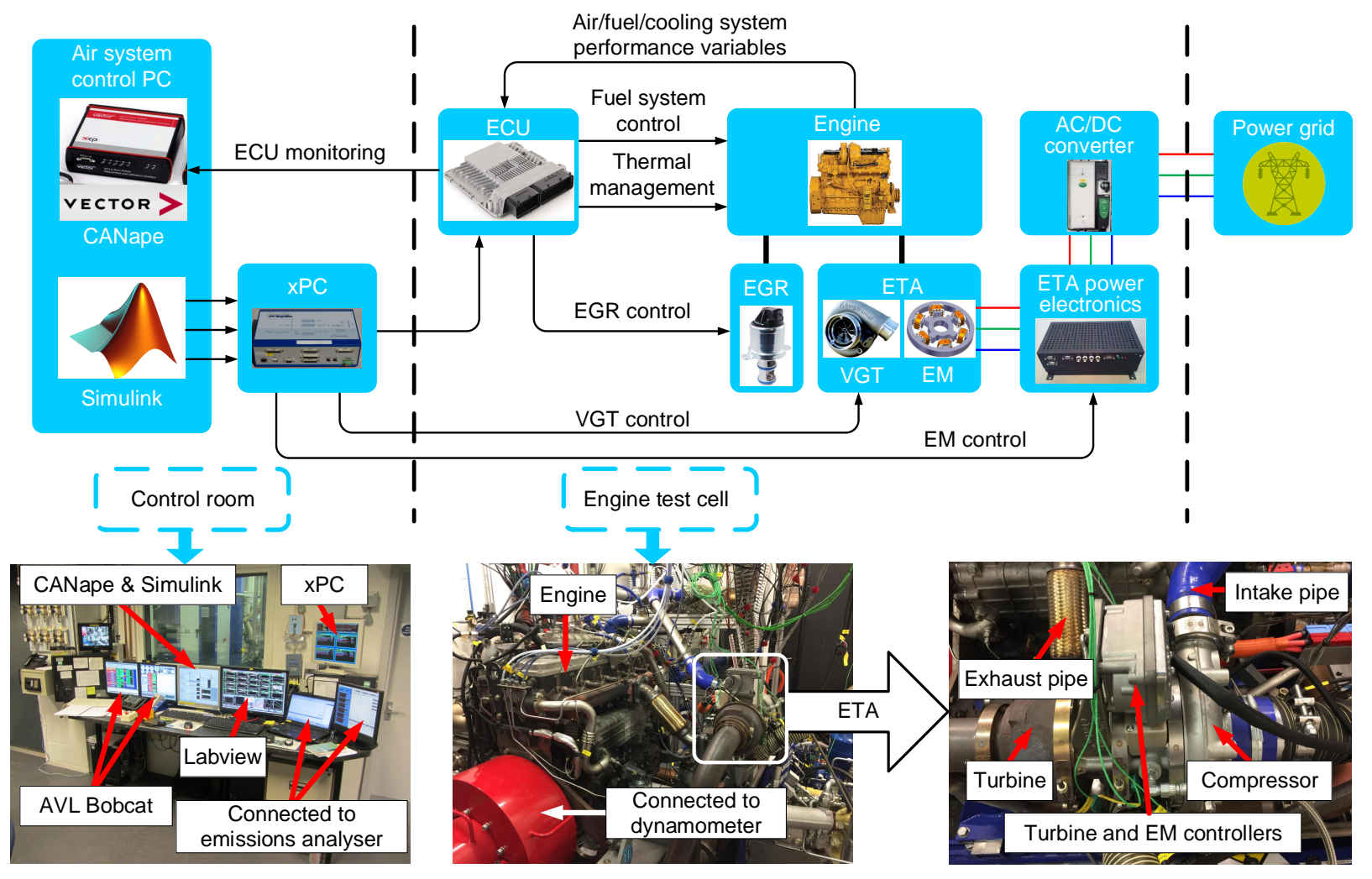

Fig. 8. Experimental setup.

Traditionally, the engine fuel economy is quantified by BSFC: $\Theta=W_{f} / P_{b}$. In the ETDE, an equivalent BSFC is defined as $\Theta_{e}=\Theta P_{\text {eq }} / P_{t}$. The control problem is formulated as

$$
\begin{aligned}
p_{\text {exh }}^{\star}=\operatorname{argmin} & \Theta_{e} \\
\text { s.t. } & u_{\min } \leq u \leq u_{\max } .
\end{aligned}
$$

2) Offline Mapping: The offline mapping is completed at specific engine operating points. In this process, $p_{\mathrm{exh}}^{\star}$ is increased in a staircase manner, while $p_{\mathrm{in}}^{\star}$ and $W_{\text {egr }}^{\star}$ are generated by the ECU. The developed EMPC controller is used to track the updated $y^{\star}$. The values of $p_{\mathrm{exh}}^{\star}$ will be feasible only if $p_{\mathrm{exh}}^{\star}$, $p_{\text {in }}^{\star}$ and $W_{\text {egr }}^{\star}$ can all be tracked for $u \in\left[u_{\min }, u_{\max }\right]$. For each feasible $p_{\mathrm{exh}}^{\star}$, the values of $\Theta, P_{t}$ and $P_{\mathrm{em}}$ will be recorded.

3) Online Optimisation: $p_{\mathrm{exh}}^{\star}$ varies according to different $s\left(\right.$ SOC) values which impact $\Theta_{e}$. To recover the battery SOC in real-time, the equivalent factor in (16) is designed as

$$
s(\mathrm{SOC})=K \Delta \mathrm{SOC}
$$

where $K$ is a positive constant to be designed, $\triangle \mathrm{SOC}=$ SOC $-\mathrm{SOC}^{\star}$, and $\mathrm{SOC}^{\star}$ is the desired value of SOC. At different SOC values, $P_{t}$ and $P_{\mathrm{em}}$ have different weights on $\Theta_{e}$, and then $p_{\text {exh }}^{\star}$ is read from the lookup table that corresponds to $\Theta_{e}^{\star}$ which holds the minimal value.

\section{VAlidation Results}

The experimental setup is based on a Cat C7.1 ACERT heavy-duty off-highway diesel engine as shown in Fig. 8. Exhaust emissions are measured using a Horiba 9000 DEGR analyser. The fuel system and thermal management are controlled by the ECU and visualised on Vector CANape. The engine speed and torque are controlled by an AVL Bobcat system. The proposed controller is built in Simulink, where the EGR control signal is sent via the ECU, and other control signals are sent from a target XPC. The calibration results from experiments have been used to set up the high fidelity physical engine model in Dynasty. Dynasty is a proprietary multiphysics simulation software developed by Caterpillar, in which the engine manifolds are modeled as 1-D components. The ranges of allowable $p_{\mathrm{exh}}^{\star}$ were calibrated in Dynasty, while the low level controller and energy management strategy were evaluated in experimental testing.

\section{A. Evaluation of the Lower Level Controller}

The control performance at $(1800 \mathrm{r} / \mathrm{min}, 120 \mathrm{~N} \cdot \mathrm{m})$ is illustrated in Fig. 9. Step changes are set on the setpoints of outputs. The engine uses about $5 \mathrm{~s}$ to stablise from cold start. In Fig. 9(a), 9(c) and 9(e), the average overshoots of $p_{\text {in }}, p_{\text {exh }}$ and $W_{\text {egr }}$ are less than $2.5 \%, 3.6 \%$ and $7.2 \%$, respectively. The root-mean-square error (RMSE) is introduced:

$$
\operatorname{RMSE}\left(y_{i}\right)=\left(\frac{1}{M} \sum_{i=0}^{M}\left|y_{i}^{\star}-y_{i}\right|^{2}\right)^{1 / 2}
$$

where $M$ is the number of tracking data samples. The RMSE of $p_{\text {in }}, p_{\text {exh }}$ and $W_{\text {egr }}$ are $2.53 \mathrm{kPa}, 2.32 \mathrm{kPa}$ and $1.63 \mathrm{~kg} / \mathrm{h}$, respectively. The settling time of all outputs are less than $1 \mathrm{~s}$. The fast and accurate tracking is because of the swift actions on actuators, as shown in Fig. 9(b), 9(d) and 9(f). The control 


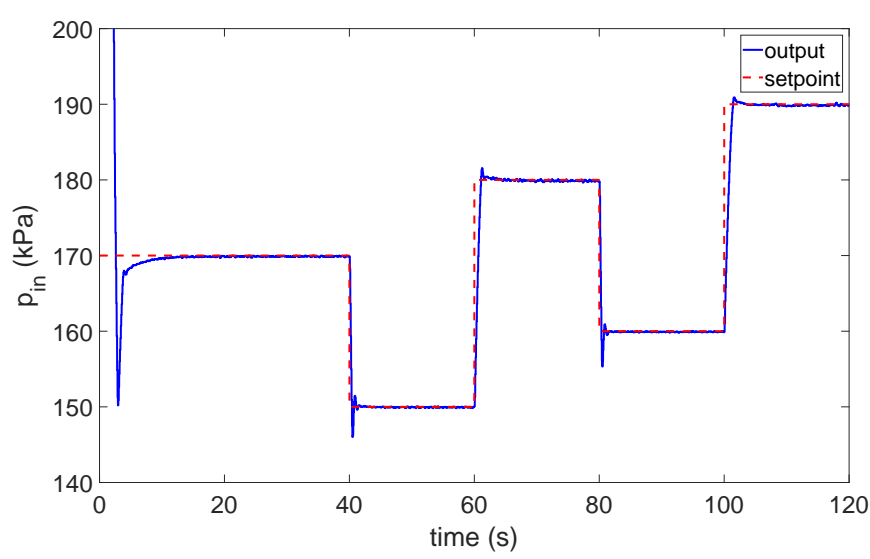

(a)

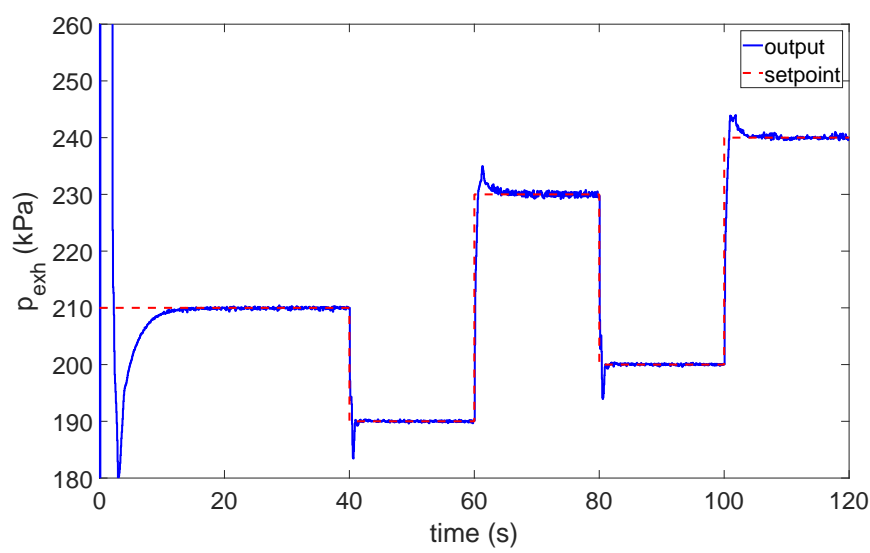

(c)

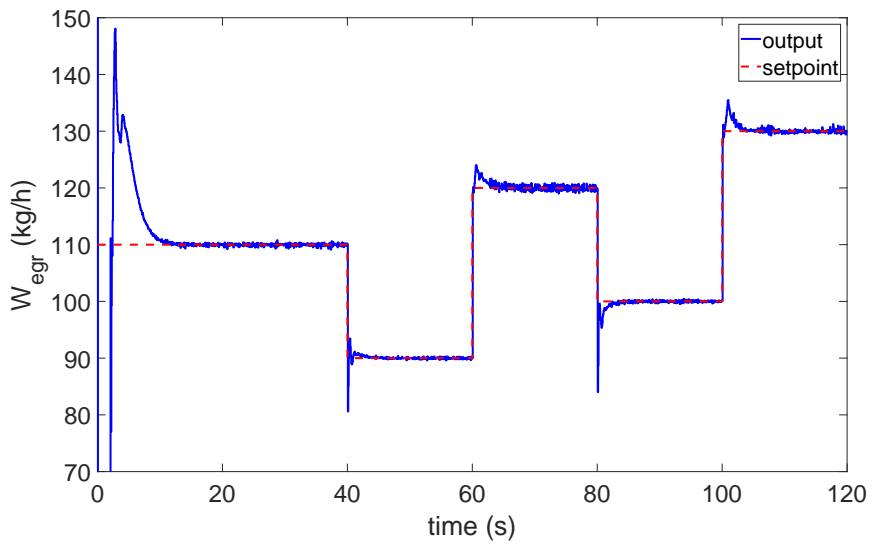

(e)

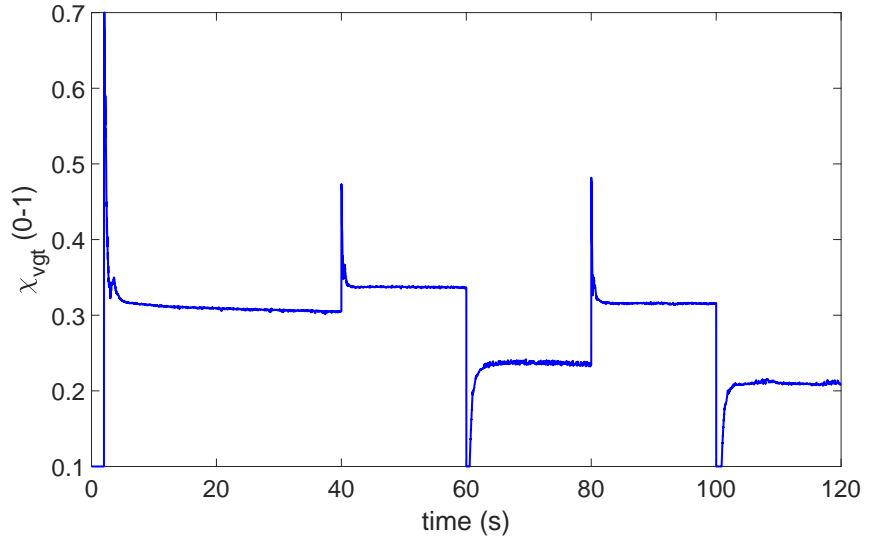

(b)

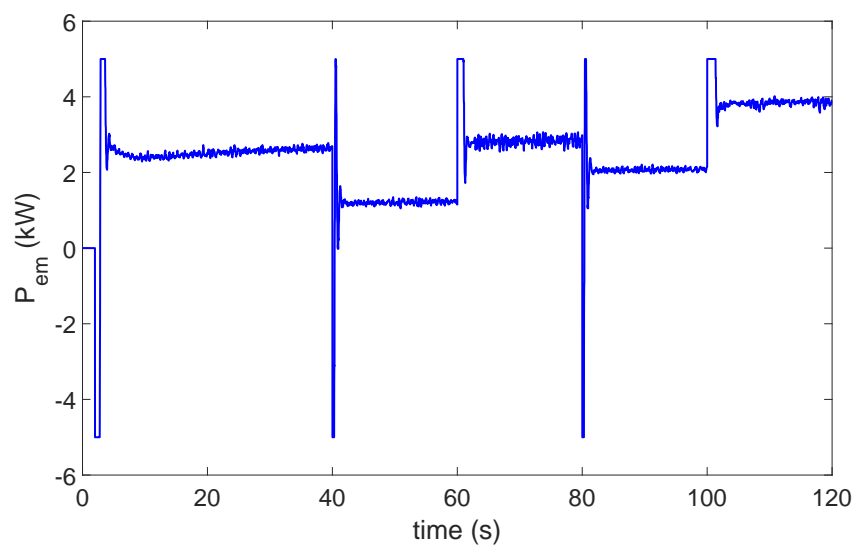

(d)

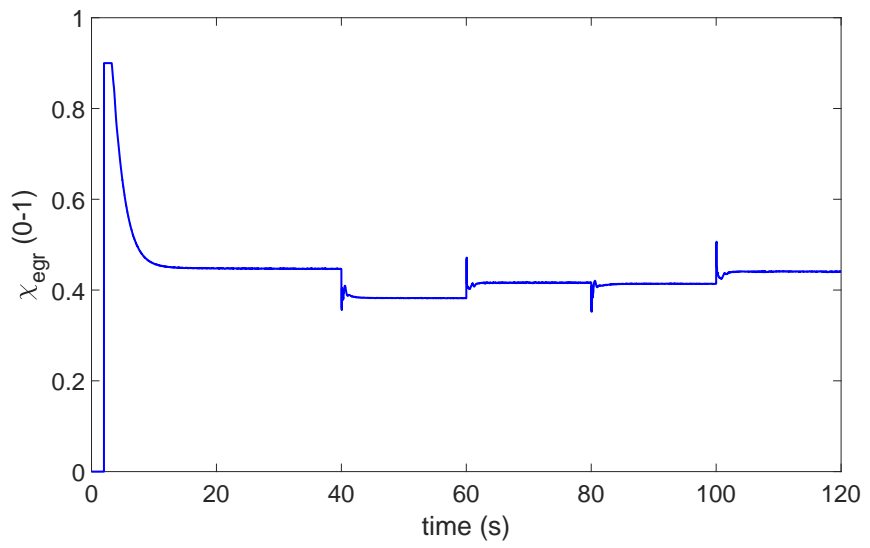

(f)

Fig. 9. Evaluation of the EMPC controller at $(1800 \mathrm{r} / \mathrm{min}, 120 \mathrm{~N} \cdot \mathrm{m})$. (a) $p_{\text {in }}$ (b) $\chi_{\mathrm{vgt} .}$ (c) $p_{\text {exh. }}$ (d) $P_{\text {em. }}$ (e) $W_{\text {egr. }}$ (f) $\chi_{\text {egr }}$.

signals can vary freely within $u_{\min }=\left[\begin{array}{lll}0.1 & -5 \mathrm{~kW} & 0\end{array}\right]^{\mathrm{T}}$ and $u_{\max }=\left[\begin{array}{lll}0.7 & 5 \mathrm{~kW} & 1\end{array}\right]^{\mathrm{T}}$.

\section{B. Evaluation of the Energy Management Strategy}

A $0.03 \mathrm{kWh}$ battery is adopted and the allowed SOC variation range is $[0.2,1]$. The integrated energy management strategy is evaluated under block loads between $120 \mathrm{~N} \cdot \mathrm{m}$ and $800 \mathrm{~N} \cdot \mathrm{m}$, while the load profile is shown in Fig. 10(a). The maximum EM motoring power is applied in load acceptance, and the maximum EM motoring power is applied in load shedding. This setting reduces the oscillation on $N$ less than
$100 \mathrm{r} / \mathrm{min}$, as shown in Fig. 10(c). The SOC is regulated to vary around the desired value as shown in Fig. 10(e), while $\mathrm{SOC}^{\star}=0.5$ and the SOC initial value is 0.2 . This is achieved by updating and tracking of the $p_{\text {exh }}^{\star}$ in real-time. Meanwhile, $p_{\text {in }}^{\star}$ and $W_{\text {egr }}^{\star}$ are both well tracked. The tracking performance of $p_{\mathrm{in}}^{\star}, p_{\mathrm{exh}}^{\star}$ and $W_{\mathrm{egr}}^{\star}$ are illustrated in Fig. 10(b), 10(d) and 10(f), respectively.

\section{Evaluation of the Controller Robustness}

The EMPC controller should maintain its robustness because it is required to be both effective in a zone and at a 


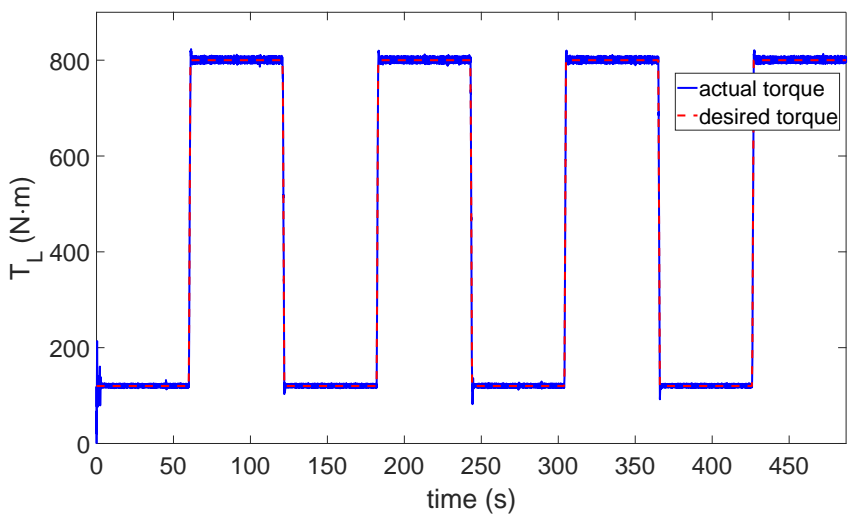

(a)

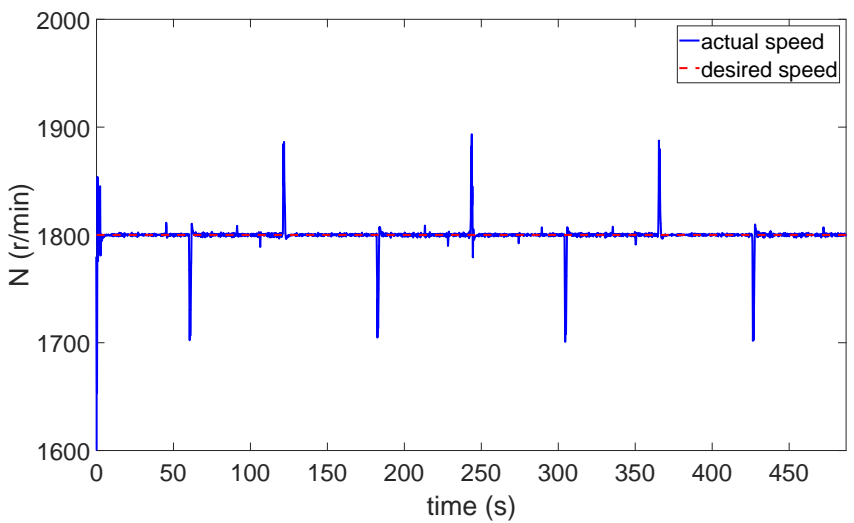

(c)

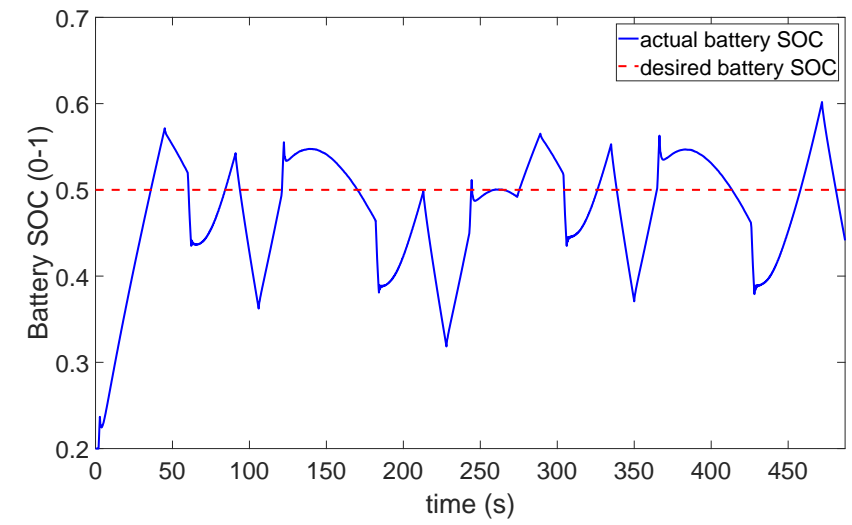

(e)

Fig. 10. Evaluation of the energy management strategy. (a) $T_{L}$. (b) $p_{\text {in }}$.

single operating point. The testing results are demonstrated in Fig. 11. The controller was tested under a series of different operating points, as shown in Fig. 11(a) and Fig. 11(c). In [0 s, $100 \mathrm{~s}], N$ is kept at $1800 \mathrm{rpm}$ while $T_{L}$ switches among $150 \mathrm{~N} \cdot \mathrm{m}, 200 \mathrm{~N} \cdot \mathrm{m}, 120 \mathrm{~N} \cdot \mathrm{m}$ and $250 \mathrm{~N} \cdot \mathrm{m}$. In [100 s, $180 \mathrm{~s}$, $T_{L}$ is kept at $120 \mathrm{~N} \cdot \mathrm{m}$, while $N$ switches among $1700 \mathrm{rpm}$, $1900 \mathrm{rpm}, 1850 \mathrm{rpm}$ and $1750 \mathrm{rpm}$. In [180 s, $260 \mathrm{~s}], N$ and $T_{L}$ are set as (1840 rpm, $\left.1760 \mathrm{rpm}, 1900 \mathrm{rpm}, 1700 \mathrm{rpm}\right)$ and $(180 \mathrm{~N} \cdot \mathrm{m}, 220 \mathrm{~N} \cdot \mathrm{m}, 140 \mathrm{~N} \cdot \mathrm{m}, 200 \mathrm{~N} \cdot \mathrm{m})$, respectively. At all of the operating points, the air system is well regulated, where the turbine speed is quickly stabilised, as shown in Fig. 11(e). $p_{\text {in }}^{\star}, p_{\text {exh }}^{\star}$ and $W_{\text {egr }}^{\star}$, are set as $170 \mathrm{kPa}, 210 \mathrm{kPa}$ and $110 \mathrm{~kg} / \mathrm{h}$, respectively. They are well tracked as demonstrated in Fig.

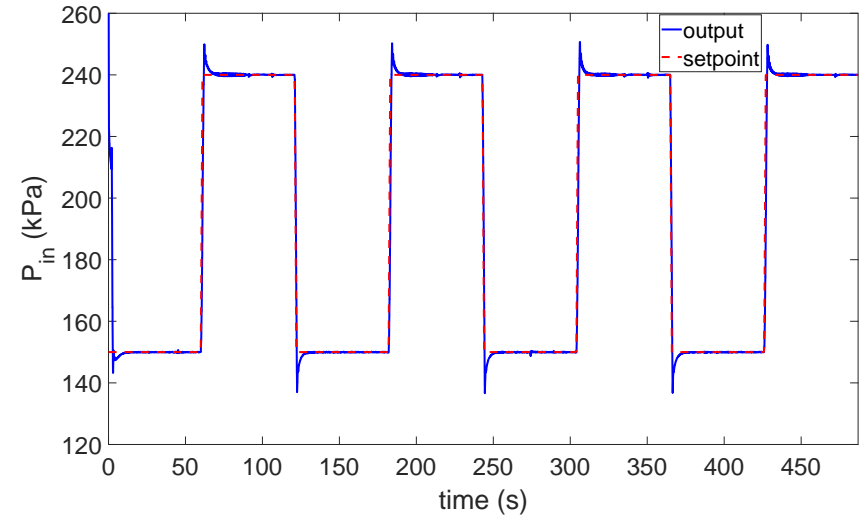

(b)

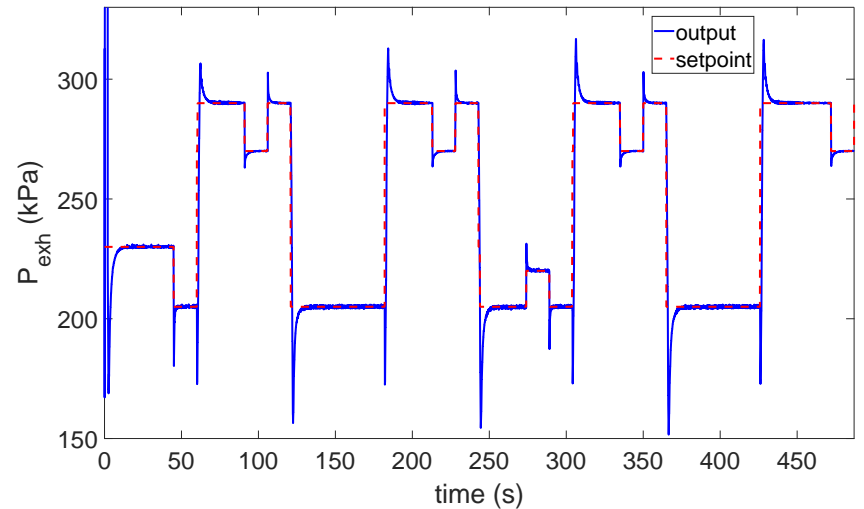

(d)

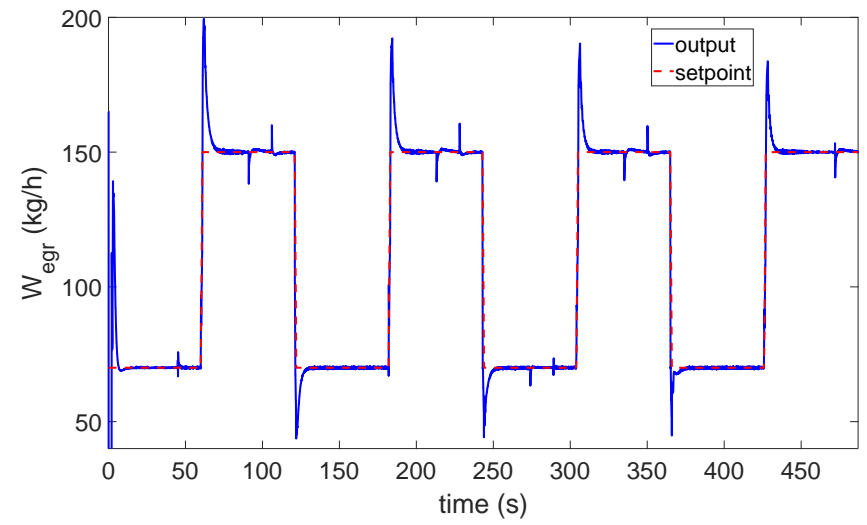

(f)

(c) $N$. (d) $p_{\text {exh }}$. (e) SOC. (f) $W_{\text {egr. }}$.

11(b), 11(d) and 11(f). This means that the EMPC controller is effective in a local operating zone once the actuators are not saturated. This is because in a local zone, the variations on the engine model is restricted to a local neighbourhood.

\section{Calibration of the Optimal Exhaust Pressure Setpoint}

The control performance at $(1800 \mathrm{r} / \mathrm{min}, 120 \mathrm{~N} \cdot \mathrm{m})$ with fixed $p_{\text {in }}^{\star}$ and $W_{\text {egr }}^{\star}$ values is illustrated in Fig. 12. $p_{\text {in }}^{\star}$ and $W_{\text {egr }}^{\star}$ are set as $150 \mathrm{kPa}$ and $70 \mathrm{~kg} / \mathrm{h}$ respectively, while $p_{\text {exh }}^{\star}$ increases as a staircase, with the initial value of $160 \mathrm{kPa}$ and the step of $5 \mathrm{kPa}$. For each step, the simulation continues for $20 \mathrm{~s}$. The tracking performance and control signals are presented in Fig. 12(a) and Fig. 12(b) respectively. The reference 


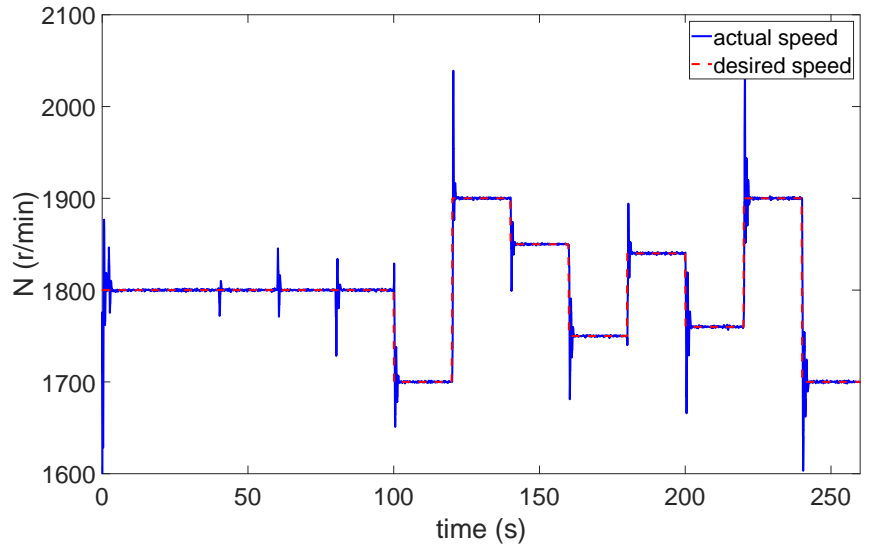

(a)

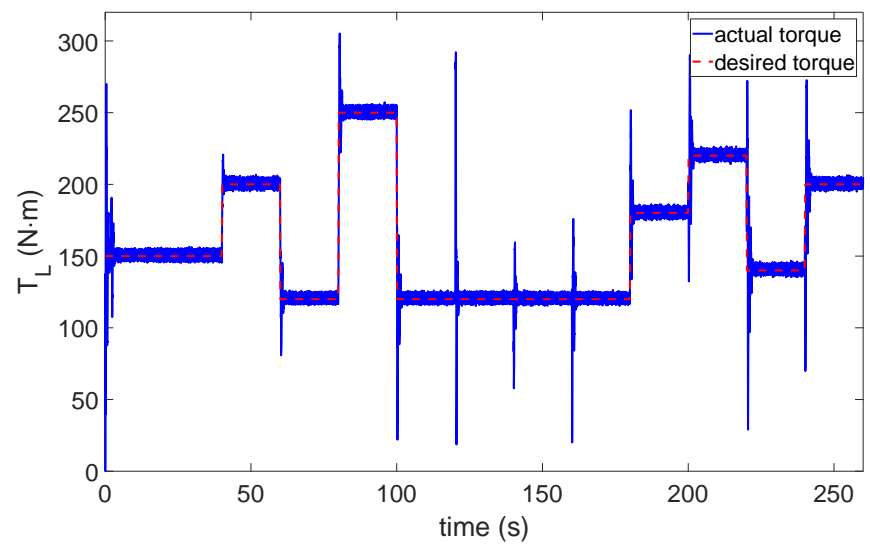

(c)

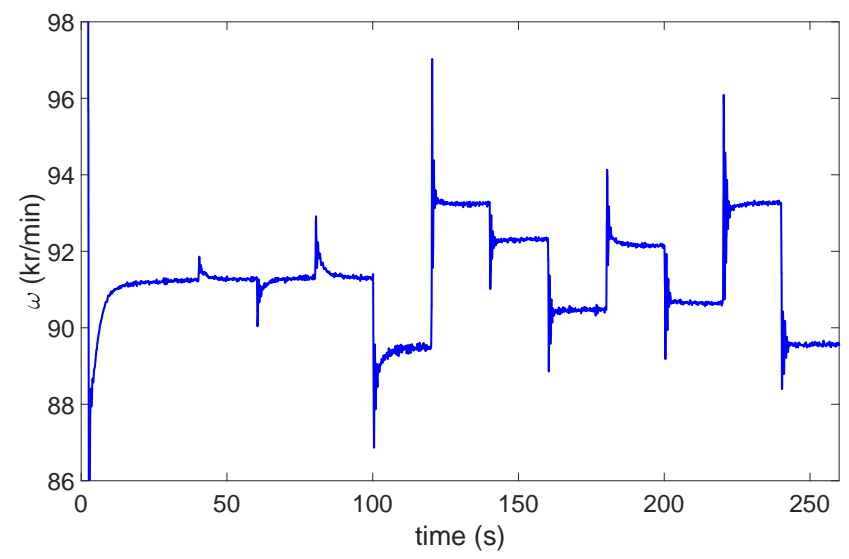

(e)

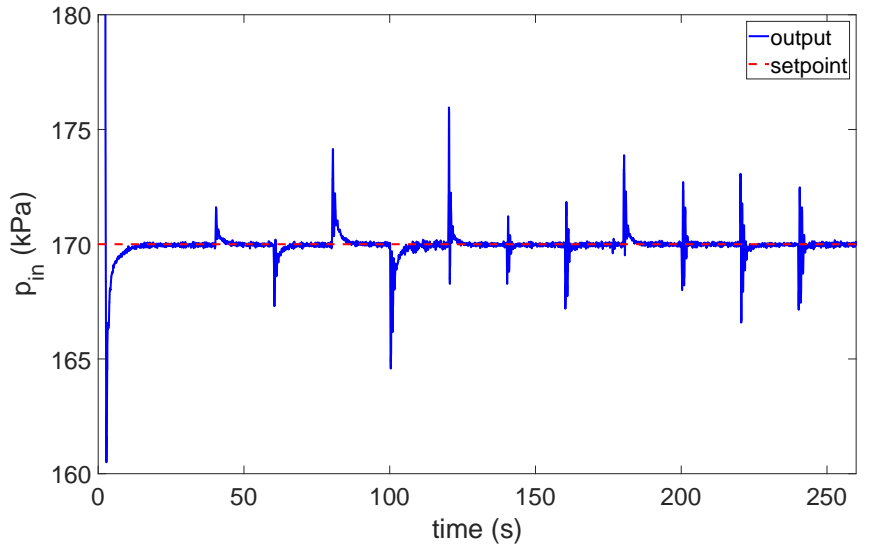

(b)

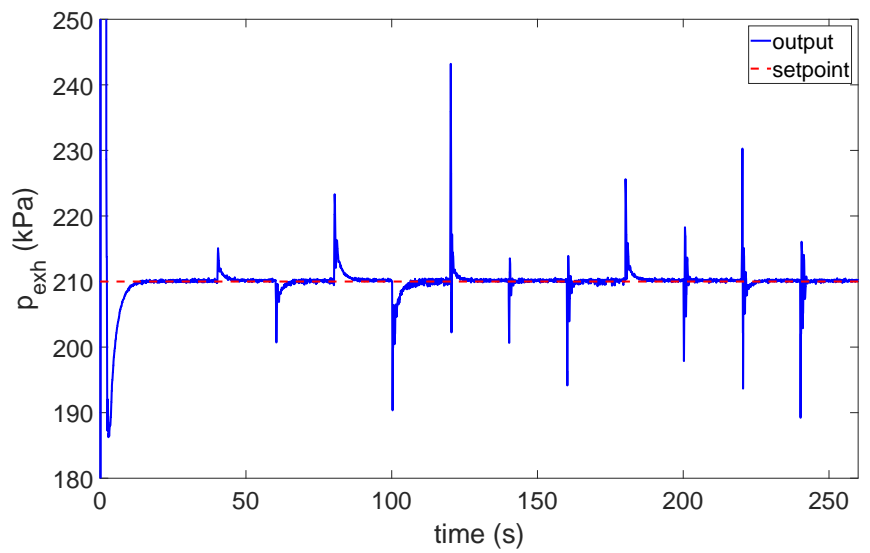

(d)

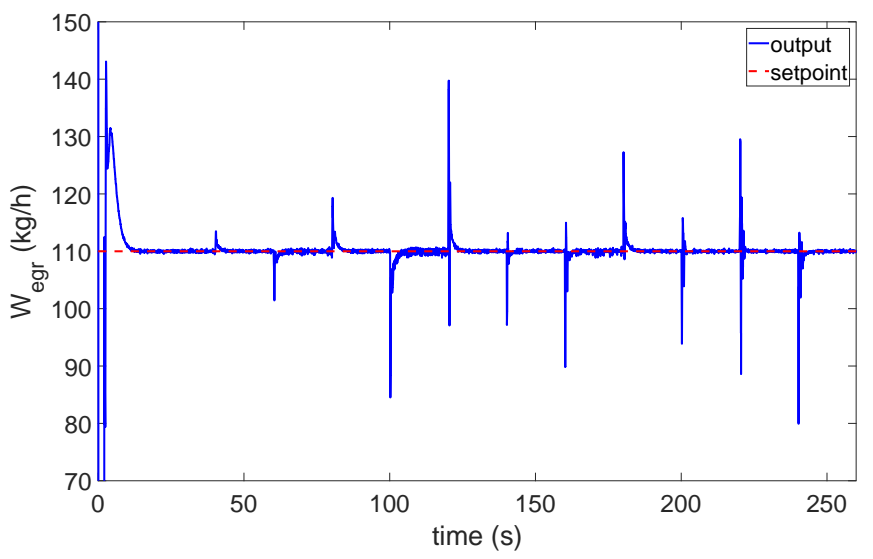

(f)

Fig. 11. Evaluation of the controller robustness at different operating points. (a) $N$. (b) $p_{\text {in. }}$ (c) $T_{L}$. (d) $p_{\text {exh }}$. (e) $\omega$. (f) $W_{\text {egr }}$.

signals are all well tracked when $p_{\text {exh }}^{\star} \leq 230 \mathrm{kPa}$. When $p_{\text {exh }}^{\star}$ increases, the turbine shaft needs to rotate slowly and therefore, the EM moves toward generating mode from motoring mode. Meanwhile, VGT moves toward closed to provide more assistance for air compression. This is to maintain the required $p_{\text {in }}$ value. On the other hand, the EGR moves toward closed too because increased $p_{\text {exh }}$ will raise $W_{\text {egr }}$ when $\chi_{\text {egr }}$ is fixed. When $p_{\text {exh }}^{\star}>230 \mathrm{kPa}, \chi_{\text {vgt }}$ will be less than 0.1 which is out of the allowed band and consequently the tracking of $p_{\mathrm{exh}}^{\star}$ will fail. Therefore, $p_{\text {exh }}^{\star} \in[160 \mathrm{kPa}, 230 \mathrm{kPa}]$ is set at low load. Based on the $P_{t}$ and $P_{\mathrm{em}}$ values recorded at different $p_{\text {exh }}$ settings, the trajectory of $p_{\text {exh }}^{\star}$ is plotted in Fig. 12(c).

\section{CONCLUSION}

A real-time energy management strategy on a state-of-theart electric turbocharger for heavy-duty ground vehicles is proposed in this paper. The performance of the ETDE in transients was tested and analysed. To improve acceleration and reduce $\mathrm{NO}_{x}$ emissions simultaneously, the ETA should be run at maximum motoring power in load acceptance and run at maximum generating power in load shedding. In steady state, an EMPC controller is analytically designed to track 

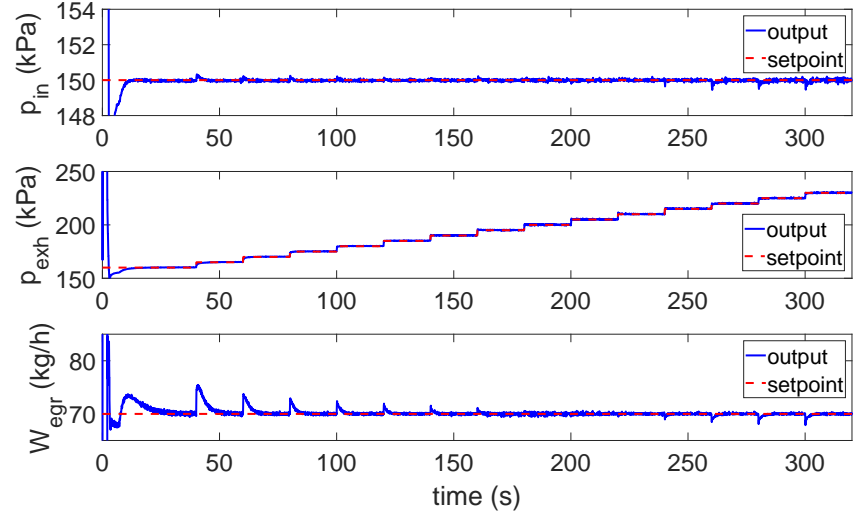

(a)
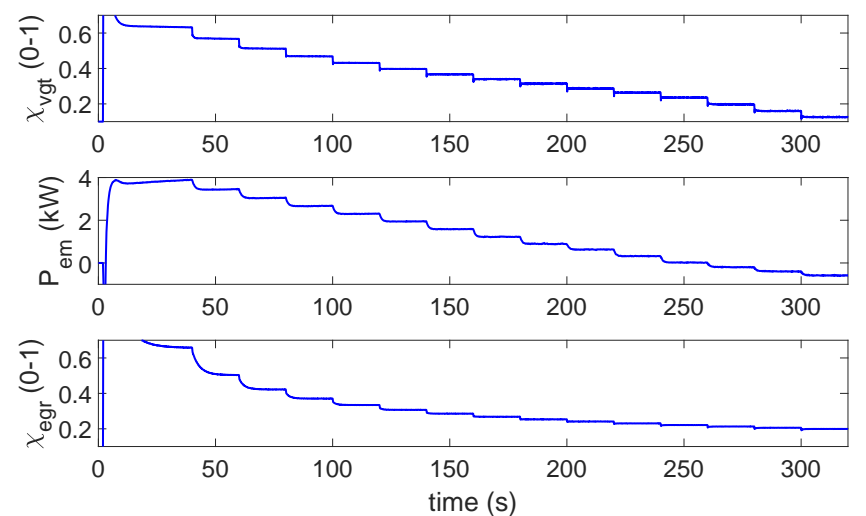

(b)

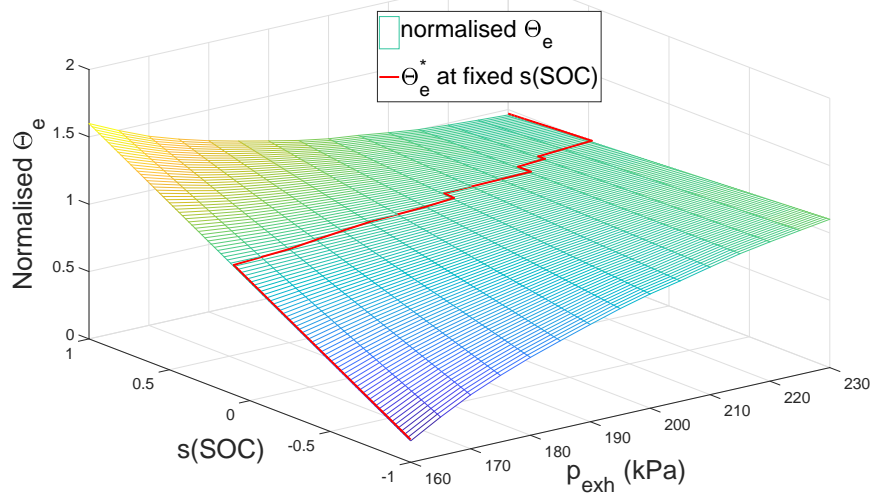

(c)

Fig. 12. Calibration of $p_{\text {exh }}^{\star}$ at $(1800 \mathrm{r} / \mathrm{min}, 120 \mathrm{~N} \cdot \mathrm{m})$. (a) Outputs regulation. (b) Control signals. (c) The trajectory of $\Theta^{\star}$ with respect to $s(\mathrm{SOC})$ and $p_{\text {exh }}$.

the setpoints of three selected outputs in a systematic way. A high level controller is designed to maximise the ETDE energy efficiency while the battery SOC is maintained around the desired value. Convincing results have been demonstrated in physical simulations and experiments. Future work will focus on the control and testing of the second generation electric turbocharger called E-Turbo.

\section{REFERENCES}

[1] World Energy Council. (2016) World energy resources 2016. [Online]. Available: https://www.worldenergy.org/wp-content/uploads/ 2016/10/World-Energy-Resources-Full-report-2016.10.03.pdf
[2] International Energy Agency. (2017) $\mathrm{CO}_{2}$ emissions from fuel combustion. [Online]. Available: https://www.iea.org/publications/freepublications/publication/ CO2EmissionsfromFuelCombustionHighlights2017.pdf

[3] G. Kalghatgi, "Is it really the end of internal combustion engines and petroleum in transport?" Appl. Energy, vol. 225, pp. 965-974, 2018.

[4] S. Chu and A. Majumdar, "Opportunities and challenges for a sustainable energy future," Nature, vol. 488, pp. 294-303, 2012.

[5] X. Xue and J. Rutledge, "Potentials of electrical assist and variable geometry turbocharging system for heavy-duty diesel engine downsizing," SAE International, pp. 2017-01-1035, 2017.

[6] Y. Yashiro, V. Jiwariyavej, Y. Yamashita, T. Hoshi, K. Terakado, and S. Ibaraki, "High speed model predictive control for next-generation turbocharging system," Mitsubishi Heavy Industries Technical Review, vol. 54, no. 1, pp. 77-81, 2017.

[7] S. Ebbesen, "Time-optimal control strategies for a hybrid electric race car," IEEE Trans. Control Syst. Technol., vol. 26, pp. 233-247, 2018.

[8] J. Dabbabi, S. Kowalik, M. Wenzelburger, and M. Buchmann, "Electrically assisted turbocharger for the 48-V board net," Pankl Turbosystems, Mannheim, Germany, Tech. Rep., 2017.

[9] Z. Ding, W. Zhuge, Y. Zhang, Y. Yin, and S. Zhang, "Performance analysis of an electric turbocompounding system for a hybrid vehicle diesel engine," in Proceedings of ASME Turbo Expo, 2015, pp. 1-10.

[10] R. Saidur, M. Rezaei, W. Muzammil, M. Hassan, S. Paria, and M. Hasanuzzaman, "Technologies to recover exhaust heat from internal combustion engines," Renew. Sustain. Energy Rev., vol. 66, pp. 56495659, 2012.

[11] M. Karvonen, R. Kapoor, A. Uusitalo, and V. Ojanen, "Technology competition in the internal combustion engine waste heat recovery: a patent landscape analysis," J. Clean. Prod., vol. 112, pp. 3735-3743, 2016.

[12] D. Singh, "A review of waste heat recovery technologies for maritime applications," Energy Convers. Manage., vol. 111, pp. 315-328, 2016.

[13] A. Shabashevich, N. Richards, J. Hwang, and P. Erickson, "Analysis of powertrain design on effective waste heat recovery from conventional and hybrid electric vehicles," Appl. Energy, vol. 157, pp. 754-761, 2015.

[14] D. Zhao, R. Stobart, G. Dong, and E. Winward, "Real-time energy management for diesel heavy duty hybrid electric vehicles," IEEE Trans. Control Syst. Technol., vol. 23, no. 3, pp. 829-841, 2015.

[15] A. Jain, T. Nueesch, C. Naegele, P. Lassus, and C. Onder, "Modeling and control of a hybrid electric vehicle with an electrically assisted turbocharger," IEEE Trans. Veh. Technol., vol. 65, no. 6, pp. 4344-4358, 2016.

[16] B. Hanko, P. Drgona, M. Danko, and M. Frivaldsky, "The use of high speed switched reluctance machine for electric turbochargers," in Proceedings of the 25th International Workshop on Electric Drives, 2017, pp. 207-212.

[17] D. Gerada et al., "Design aspects of high speed high power density laminated rotor induction machines," IEEE Trans. Ind. Electron., vol. 58 , no. 9, pp. 4039-4047, 2011.

[18] F. Crescimbini, "High-speed electric drive for exhaust gas energy recovery applications," IEEE Trans. Ind. Electron., vol. 61, no. 6, 2014

[19] E. Winward, J. Rutledge, J. Carter, A. Costall, R. Stobart, D. Zhao, and Z. Yang, "Performance testing of an electrically assisted turbocharger on a heavy duty diesel engine," in Proc. 12th Int. Conf. Turbochargers Turbocharging, 2016.

[20] R. Kiwan, B. Middleton, and A. Stefanopoulou, "Thermodynamic and practical benefits of waste energy recovery using an electric turbogenerator under different boosting methods," SAE International, pp. 2018-01-0851, April 2018.

[21] H. Aghaali and H. Angstrom, "A review of turbocompounding as a waste heat recovery system for internal combustion engines," Renew. Sustain. Energy Rev., vol. 49, pp. 813-824, 2015.

[22] D. Zhao, E. Winward, Z. Yang, R. Stobart, B. Mason, and T. Steffen, "An integrated framework on characterization, control and testing of an electrical turbocharger assist," IEEE Trans. Ind. Electron., vol. 65, no. 6, pp. 4897-4908, 2018.

[23] S. Ibaraki, Y. Yamashita, K. Sumida, and H. Ogita, "Development of the hybrid turbo, an electrically assisted turbocharger," Mitsubishi Heavy Industries Technical Review, vol. 43, no. 3, pp. 1-5, 2006.

[24] K. Ekberg and L. Eriksson, "Improving fuel economy and acceleration by electric turbocharger control for heavy duty long haulage," IFAC Papers Online, vol. 50, no. 1, pp. 11 052-11 057, 2017.

[25] B. Glenn, D. Upadhyay, and G. Washington, "Control design of electrically assisted boosting systems for diesel powertrain applications," IEEE Trans. Control Syst. Technol., vol. 18, no. 4, pp. 769-778, 2010. 
[26] A. Stefanopoulou, I. Kolmanovsky, and J. Freudenberg, "Control of variable geometry turbocharged diesel engines for reduced emissions," IEEE Transactions on Control Systems Technology, vol. 8, no. 4, pp. $733-745,2000$.

[27] H. Aghaali and H. Ångström, "Demonstration of air-fuel ratio role in one-stage turbocompound diesel engines," SAE International, pp. 201301-2703, 2013.

[28] Y. Wang, I. Haskara, and O. Yaniv, "Quantitative feedback design of air and boost pressure control system for turbocharged diesel engines," Control Engineering Practice, vol. 19, pp. 626-637, 2011.

[29] J. Desantes, J. Galindo, C. Guardiola, and V. Dolz, "Air mass flow estimation in turbocharged diesel engines from in-cylinder pressure measurement," Experimental Thermal and Fluid Science, vol. 34, pp. 37-47, 2010.

[30] M. Zheng, G. Reader, and J. Hawley, "Diesel engine exhaust gas recirculation - a review on advanced and novel concepts," Energy Conversion and Management, vol. 45, pp. 883-900, 2004.

[31] L. Ljung, System identification: theory for the user. New Jersey, US: Prentice Hall, 1999.

[32] P. Overschee and B. Moor, "N4sid: subspace algorithms for the identification of combined deterministic-stochastic systems," Automatica, vol. 30, no. 1, pp. 75-93, 1994.

[33] T. Mckelvey, "Fully parametrized state-space models in system identification," Proceedings of the IFAC Symposium on System Identification, vol. 27, no. 8, pp. 669-674, 1994.

[34] A. Bemporad, M. Morari, V. Dua, and E. Pistikopoulos, "The explicit linear quadratic regulator for constrained systems," Automatica, vol. 38, pp. 3-20, 2002.

[35] A. Bemporad, F. Borrelli, and M. Morari, "Model predictive control based on linear programming: The explicit solution," IEEE Transactions on Automatic Control, vol. 47, no. 12, pp. 1974-1985, 2002.

[36] J. Garriga and M. Soroush, "Model predictive control tuning methods: a review," Ind. Eng. Chem. Res., pp. 3505-3515, 2010.

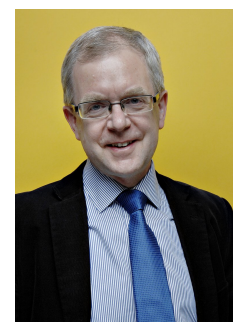

Richard Stobart (M'93) received the B.S. (Hons) degree in mechanical engineering from the University of Cambridge, Cambridge, U.K. in 1979.

He worked in commercial R\&D from 1979 to 2001 when he was appointed Professor of Automotive Engineering at the University of Sussex, Brighton, U.K., where he was also the Head of Engineering and Design from 2003 to 2006. In 2007 he was appointed Professor of Automotive Engineering at Loughborough University, Loughborough, U.K., and from 2008 to 2011 was Head of Aeronautical and Automotive Engineering. In 2016 he retired from his full time position as Professor of Powertrain Systems, and as Professor Emeritus continues to work in research in the fields of energy recovery and engine control.

Prof. Stobart was a member of the team who, in 1997, was a recipient of the Arthur D Little Ketteringham Prize for innovation in the design of fuel cell power systems. He was elected Fellow of the UK Institution of Mechanical Engineers in 2000 and Fellow of the Society of Automotive Engineers (SAE) in 2014. He is currently Chair of the U.K. Section of SAE International.

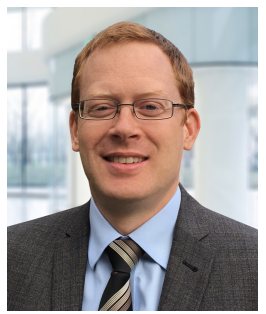

Byron Mason received the B.E. degree in mechanical engineering and the Ph.D. degree in powertrain calibration and control from the University of Bradford, U.K., in 2005 and 2009, respectively. From 2007 to 2015 he was Lecturer, then Senior Lecturer in mechanical engineering at the University of Bradford. He is currently a Senior Lecturer in intelligent powertrain systems with the Department of Aeronautical and Automotive Engineering, Loughborough University, Loughborough, U.K.

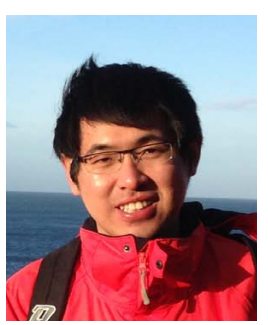

Dezong Zhao (M'12-SM'17) received the B.S. and M.S. degrees in control science and engineering from the School of Control Science and Engineering, Shandong University, Jinan, China, in 2003 and 2006, respectively, and the Ph.D. degree in control science and engineering from the Department of Automation, Tsinghua University, Beijing, China, 2010.

Since 2017, he has been a Lecturer in intelligent systems with the Department of Aeronauti$\mathrm{cal}$ and Automotive Engineering, Loughborough University, Loughborough, U.K. Since 2018, he has been an EPSRCUKRI Innovation Fellow in robotics and artificial intelligence systems. His research interests include artificial intelligence, autonomous vehicles, low carbon vehicles, and nonlinear control theory and applications.

Dr. Zhao was a recipient of the Excellence 100 Campaign of Loughborough University. 